\title{
Audit of the community-directed treatment with ivermectin (CDTI) for onchocerciasis and factors associated with adherence in three regions of Cameroon
}

Guy-Roger Kamga ${ }^{1,2,3^{*}}$, Fanny N. Dissak-Delon ${ }^{1,2,4}$, Hugues C. Nana-Djeunga ${ }^{2,5}$, Benjamin D. Biholong ${ }^{1}$, Stephen Mbigha Ghogomu ${ }^{6}$, Jacob Souopgui ${ }^{4}$, Joseph Kamgno ${ }^{2,7}$ and Annie Robert ${ }^{3}$

\begin{abstract}
Background: After more than 15 years of community-directed treatment with ivermectin (CDTI) in the Centre 1, Littoral 2 and West CDTI projects in Cameroon, the epidemiological evaluation conducted in 2011 revealed that onchocerciasis endemicity was still high in some communities. To investigate the potential reasons explaining this high endemicity, a cluster coverage survey was conducted in April-May 2015 in three health districts (HD), to assess the implementation of the CDTI, the 2014 therapeutic coverage and the five-year adherence to treatment. A twostage cluster design was considered during analyses, with data weighted proportionally to age and gender distribution in the population.

Results: In the three HDs, 69 community leaders, 762 heads of households, 83 community drug distributors (CDD) and 2942 household members were interviewed. The CDTI organization and the involvement of heads of households were in average weak, with $84.0 \%$ (95\% Cl: 81.2-86.4\%) of them who had not participated in activities during the 2014 mass drug administration (MDA). On average, six of ten community leaders declared that the period of treatment was decided by the health personnel while the CDDs selection was made during a community meeting for only $43.4 \%$ of them. The 2014 weighted therapeutic coverage was $64.1 \%$ (95\% Cl: 56.8-70.9\%), with no significant difference in the three HDs. The survey coverages were lower than the reported coverages with a significant difference varying from 14. $1 \%$ to $22.0 \%$. Among those aged 10 years and above, 57.8\% (95\% Cl: 50.2-65.1\%) declared having taken the treatment each time during the last five MDAs with no significant difference among HDs, while $9.8 \%$ (95\% Cl: 7.5-12.8\%) declared that they had never taken the drug. In multivariate analysis, the most important factors associated with the five-year adherence to treatment were high involvement in CDTI and age (40+ years).

Conclusions: Despite more than 15 years of CDTI, there was still weak community participation and ownership, a lower coverage than reported and an average five-year adherence in the surveyed HDs. The reinforcement of the community ownership by the Ministry of Public Health officials and the timely procurement of ivermectin as requested by the communities are some measures that should be implemented to improve the therapeutic coverage, adherence to treatment and hence achieve onchocerciasis elimination. Further anthropological and entomological studies would provide better insights into our understanding of the persistence of the disease in these three CDTI projects.
\end{abstract}

Keywords: Onchocerciasis, Ivermectin, Persistence, Treatment coverage, Adherence, Cameroon

\footnotetext{
* Correspondence: guyrogerkgr@yahoo.fr

${ }^{1}$ Ministry of Public Health, No8, Rue 3038 quartier du Lac, Yaoundé,

Cameroon

${ }^{2}$ Centre for Research on Filariasis and other Tropical Diseases (CRFilMT), P.O.

Box 5797, Yaoundé, Cameroon

Full list of author information is available at the end of the article
}

(c) The Author(s). 2018 Open Access This article is distributed under the terms of the Creative Commons Attribution 4.0 International License (http://creativecommons.org/licenses/by/4.0/), which permits unrestricted use, distribution, and reproduction in any medium, provided you give appropriate credit to the original author(s) and the source, provide a link to the Creative Commons license, and indicate if changes were made. The Creative Commons Public Domain Dedication waiver (http://creativecommons.org/publicdomain/zero/1.0/) applies to the data made available in this article, unless otherwise stated. 


\section{Background}

Onchocerciasis, better known as river blindness, is a debilitating insect-borne parasitic disease caused by Onchocerca volvulus and transmitted via the bites of blackflies of the genus Simulium. Clinical manifestations associated with this filarial infection include severe itching, disfiguring skin conditions, and visual impairment which can lead to permanent blindness. Onchocerciasis is a neglected tropical disease (NTD) that creates stigma, generates and perpetuates poverty and is an impediment to socioeconomic development. The disease is currently endemic in 31 African countries, in Yemen and in two localized foci of two Latin American countries (Brazil and Venezuela). The disease used to be endemic in six countries of the Americas, but control efforts led in the elimination of the disease in four of them (Columbia in 2013, Ecuador in 2014, Mexico in 2015 and Guatemala in 2016) [1]. About 99\% of the estimated 198 million people living in areas where transmission of the parasite is likely to occur are in Africa [2]. From the latest estimates, the prevalence of infection is about 17 million, although the likelihood that this figure might be underestimated is high [3].

Ivermectin is currently the only known effective and safe drug used for mass treatments against onchocerciasis. Although highly effective against microfilariae, its macrofilaricidal activity is quite modest, and microfilariae release by adult worms resume just a few months after treatment. Thus, treatments must be repeated, for at least $12-15$ years, to comply with the quite long reproductive lifespan of the adult worm [4, 5]. The community-directed treatment with ivermectin (CDTI), proposed by the World Health Organization (WHO) through the African Program for Onchocerciasis Control (APOC), has significantly improved ivermectin treatment coverage [6-8], leading to a quite successful control of onchocerciasis. Indeed, reports support improvements in the coverage, both geographical and therapeutic, as the total number of treatments delivered increased gradually to reach 132 million in 2016 in the African region [2].

Despite this effort in increasing drug coverage, the disease persists in some foci. Indeed, recent phase $1 \mathrm{~A}$ surveys conducted in 2011 by WHO/APOC revealed onchocerciasis prevalence above $60 \%$ in some foci of the Centre 1, Littoral 2 and West CDTI projects in Cameroon [9]. The reasons for such persistence of the infection are yet to be elucidated, and it is not clear whether this is due to low treatment coverage, systematic non-adherence of a proportion of the population (so-called systematic non-compliers), high transmission of the infection or suboptimal response of the parasite to ivermectin. In the aforementioned CDTIs projects, the reported coverages were always above the $65 \%$ threshold required to control the disease [10]. However, no study has confirmed those coverages. Coverage rates in a community may not give the full picture of program success because there may be individuals or groups who systematically do not comply over the years, and thus contribute to the transmission of the disease. A study on the adherence with eight years of annual ivermectin treatment in Cameroon and Nigeria showed that only $42.9 \%$ of the participants took six to eight treatments [11]. It has been suggested that age, gender, the perception of the susceptibility to be infected by the disease, CDTI organization, and some socio-economic characteristics of the population can influence the adherence to treatments [11-15].

The objective of the present survey was to understand the reasons explaining the persistence of onchocerciasis in three CDTI projects (Centre 1, Littoral 2 and West) in Cameroon by assessing: (i) the implementation of the CDTI; (ii) the 2014 MDA coverage; and (iii) the factors influencing the adherence to the treatment in these CDTI projects.

\section{Methods}

\section{Study area}

The present study was conducted in the Bafia $\left(4^{\circ}\right.$ $\left.45^{\prime} 00^{\prime \prime N}, 11^{\circ} 14^{\prime} 00^{\prime \prime E}\right)$, Foumbot-Massangam $\left(5^{\circ} 30^{\prime} 28^{\prime \prime} \mathrm{N}\right.$, $\left.10^{\circ} 37^{\prime} 57^{\prime \prime} \mathrm{E}\right)$ and Yabassi $\left(4^{\circ} 27^{\prime} 16^{\prime \prime} \mathrm{N}, 9^{\circ} 57^{\prime} 56^{\prime \prime} \mathrm{E}\right)$ health districts (HD), belonging to the Centre 1, West and Littoral 2 CDTI projects, respectively (Fig. 1).

The Bafia HD belongs to the Mbam and Inoubou Division (Centre Region), situated at $120 \mathrm{~km}$ north from Yaoundé, the political capital of Cameroon. In 2014, its population was estimated at 226,073 inhabitants, based on a census conducted by community drug distributors (CDD). The altitude of this Region varies from 1100 to $1300 \mathrm{~m}$. It is a forest-savanna transition zone, irrigated by many fast-flowing rivers including the Sanaga and its tributaries, the main ones being the Mbam and the Noun rivers. The main activities of inhabitants are agriculture (mainly cocoa), fishing and sand mining.

The Foumbot-Massangam health district (currently split into two health districts) belongs to the Noun Division (West Region), at $25 \mathrm{~km}$ from Bafoussam, the regional capital. Census conducted by CDDs prior to the 2014 MDA revealed that its population was estimated at 132,847 inhabitants. It is a forest-savanna transition zone, irrigated by many fast-flowing rivers including the tributaries of the Sanaga in the east (Nkoup, Noun) that favor development of permanent blackflies' breeding sites throughout the year. The relief of the region is mountainous with altitude varying from as low as $500 \mathrm{~m}$ in the Noun and Nkam valleys to $1000-2500 \mathrm{~m}$ in Western High Plateau. Agriculture is the main activity, involving at least $80 \%$ of inhabitants. 


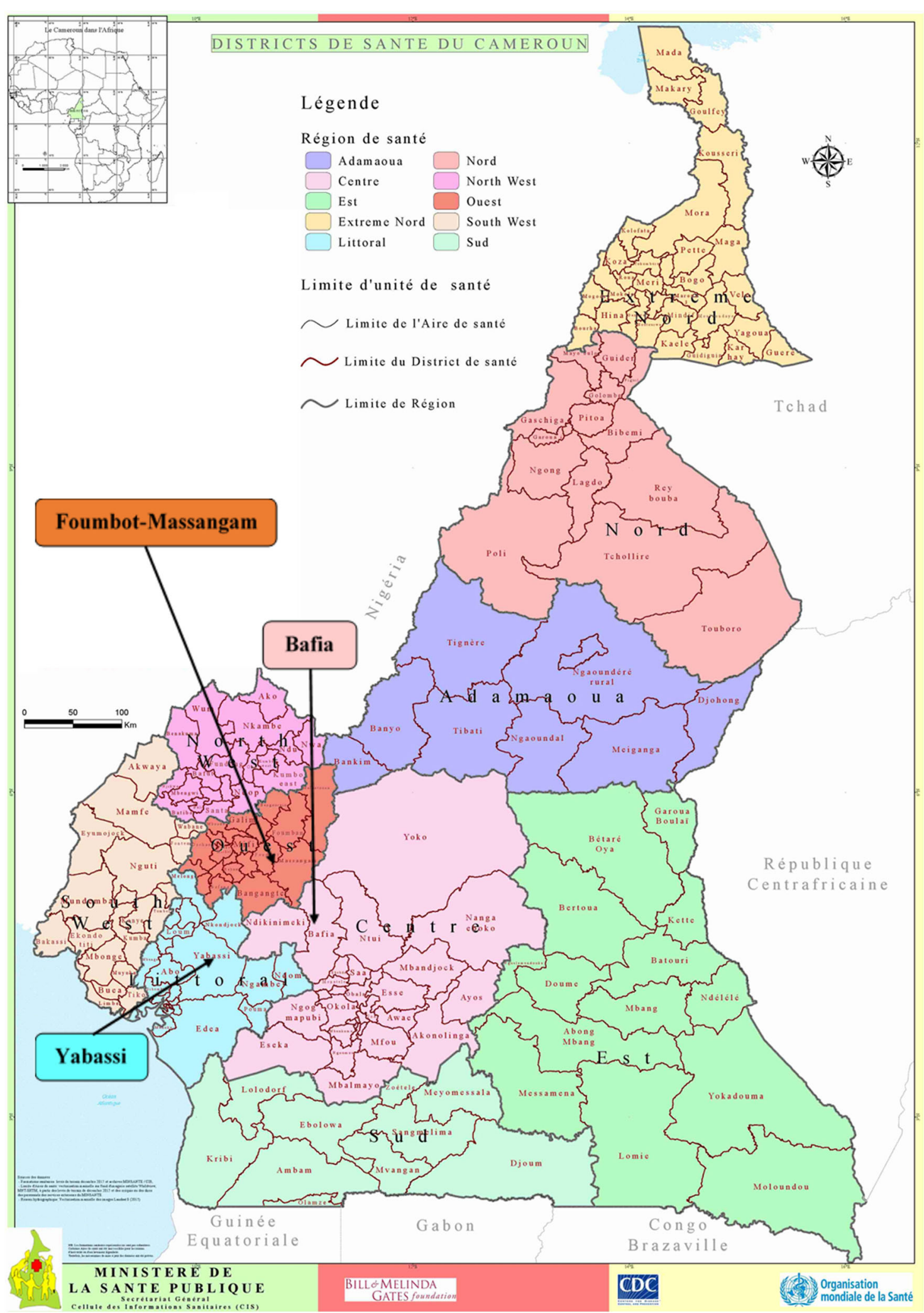

Fig. 1 Map of Cameroon showing the surveyed health districts (source: 2016 @ MINSANTE\SG Cellule des Informations Sanitaires; https://www.dhis-minsante-cm.org/portal/ ) 
The Yabassi HD belongs to the Nkam Division (Littoral Region), at $100 \mathrm{~km}$ north-east from Douala, the economic capital of the country. According to the 2014 CDD census, its population was estimated at 21,459 inhabitants. The relief is undulating, showing an alternation of valleys and plains. The altitude of the Region varies between $10-800 \mathrm{~m}$. This health district is also irrigated by many fast-flowing rivers comprising Nkam, Dibamba, Mabombé, Njanga, and Mahé which are favorable to blackfly breeding. The vegetation is mainly dense humid forest. Agriculture is the main activity, involving at least $60 \%$ of inhabitants.

\section{Study design}

A cross-sectional survey was conducted in April and May 2015 in the health districts of Yabassi (Littoral Region), Bafia (Centre Region) and the former district of Foumbot-Massangam (West Region). Surveyed health districts were selected according to the results of the follow up epidemiologic evaluation carried out in 2011 by Katabarwa et al. [16] as well as the National Onchocerciasis Control Programme (unpublished report), revealing a persistence of high prevalence in those health districts, despite good reported therapeutic coverage [10]. Indeed, the three CDTI projects (Littoral 2, Centre 1 and West) reported sustained coverage above $70 \%$ during the last ten years. It should be noted that the formal CDTI started in 1999 in the Littoral 2, and in 2000 in the Centre 1 and the West projects, with a progressive enrollment of communities [10]. The reported therapeutic coverage achieved, calculated over the entire population, progressively increased from as low as $30 \%$ to above $80 \%$, with some variations among projects as illustrated in Fig. 2. During the last five years/rounds of treatment, the treatment coverage was at least $75 \%$ in each CDTI project.

The selection of the clusters and the households was done following the World Health Organization guidelines for immunization coverage surveys $[17,18]$. A total of 30 clusters (communities or villages) were selected in each health district according to the probability proportional to estimated size (PPES) strategy using the 2014 population figures obtained from the CDDs' census.

\section{Data collection}

In each cluster, eight households were randomly selected by a trained research assistant using the random walk method [19]. All the individuals living in a selected household, regardless of treatment eligibility, were interviewed about the last five MDA against onchocerciasis. Those who were present were asked to name all the current residents of the household and validate their age, sex, educational level, other socio-economic characteristics and their treatment status. Individual adherence to mass treatment was assessed by asking each participant if he/she swallowed ivermectin tablets during each of the previous five years (including the last CDTI-campaign). Ivermectin tablets were presented to the participants to make sure that the interview was targeting the right treatment. The treatment status of less than 10 years-old was given by their parents or caretakers. The members present were also asked about reasons any member did not take ivermectin during the 2014 distribution.

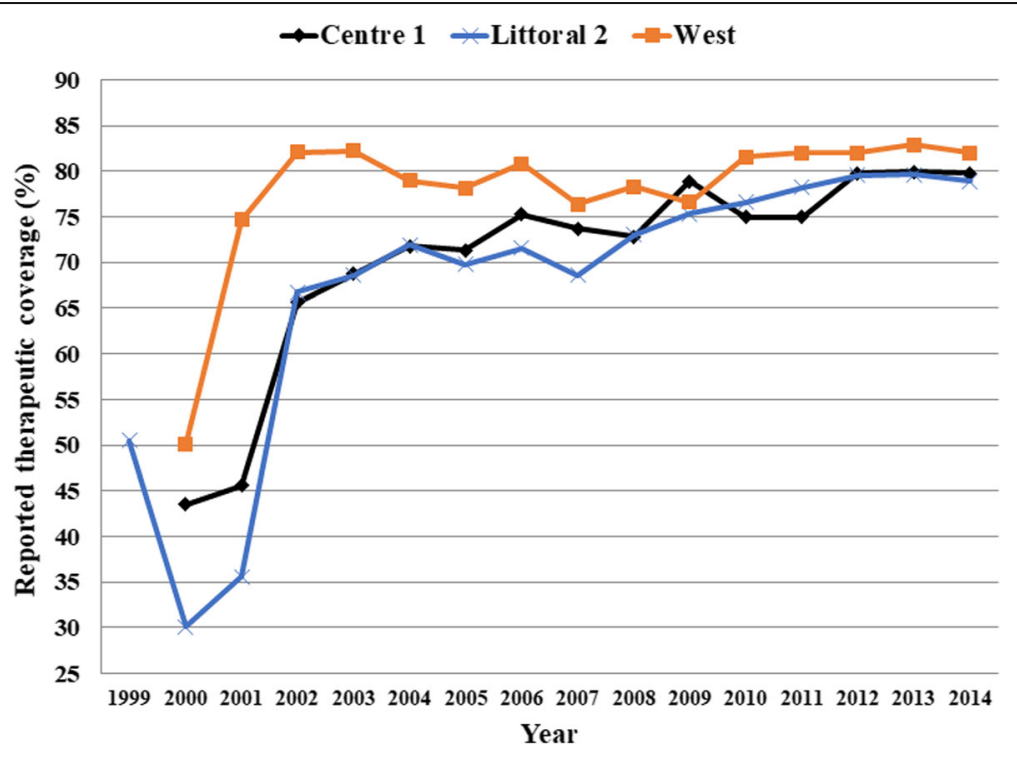

Fig. 2 Therapeutic coverage of community-directed treatment with ivermectin in the Centre 1, Littoral 2 and West CDTI projects between 1999 and 2014 
Once all the data were collected in a household, the research assistant attempted to compare interviewee declarations with the records in the CDDs registries. Unfortunately, it was not possible to cross-check the registries with the questionnaire data due to many reasons in all the surveyed districts: unavailable registries; lost registries destroyed by floods, fire; missing. Thus, from the survey data, treatment coverages were calculated and compared to 2014 treatment data reported by the health system. Data collection was done using a pre-tested questionnaire by the same research assistants in all HDs.

In each selected cluster, the community leader was interviewed, and one CDD was randomly chosen among the CDDs if they were more than one to work in the selected community using a specific questionnaire for each group.

\section{Assessment of the conduct of the CDTI}

The interviews of the heads of the households, the community leaders, and the community drug distributors were conducted using specific questionnaires for each group to assess the organization of the CDTI and their involvement. This, summarized as "involvement of the head of household", used seven criteria to classify the overall CDTI process ("weak" for 0-3/7; "average" for 45/7; and "good" for 6-7/7 criteria achieved). These criteria and the reference answer (in parentheses) were: (i) the place of distribution (household); (ii) the actors responsible for the choice of the place of distribution (community members during a meeting); (iii) the involvement in the choice of the place of distribution (yes); (iv) the involvement in social mobilization activities (yes); (v) the actors responsible for the choice of CDDs (community members during a meeting); (vi) the involvement in the choice of CDDs (yes); and (vii) whether the interviewee attended health education sessions on onchocerciasis and its treatment in 2014 (yes). Each criterion received one point for the reference answer.

\section{Data analysis}

All relevant data were recorded into a purpose-built Microsoft Access database and subsequently exported into STATA 13.1 for statistical analysis. As in a selected household, all the permanent residents were interviewed, the weighting was used to consider the difference in the population structure in terms of gender and age. The weighting was done according to the 2015 national demographic data projections [20]. Considering the cluster sampling, the design-adjusted Rao-Scott version of Pearson's chi-square test $(\mathrm{F})$ was used to compute in each health district, the 2014 treatment coverages, and the five-year adherence in the univariate analysis along with their 95\% confidence intervals (CI) [21]. All variables having a $P$-value $<0.10$ in univariate analysis were entered into a multiple logistic regression model to determine factors independently associated with the five-year adherence. The final model is reported with adjusted odds ratio (AOR) and 95\% confidence interval (CI) for variables associated with the five-year adherence. $P$-values were corrected according to the Bonferroni method for multiple testing. We considered a $P$-value $<5 \%$ as indicative of a statistically significant result.

The following terms defined below by the WHO [22] and endorsed by Krentel et al. [23] and Shuford et al. [24], were calculated or used for analysis: therapeutic coverage, programmatic coverage, reported coverage, five-year adherence.

\section{Therapeutic (epidemiological) coverage}

The proportion of individuals in the survey area who have swallowed ivermectin, out of the total population in the survey area, regardless of treatment eligibility.

\section{Programmatic coverage}

The proportion of individuals in the survey area who have swallowed ivermectin, out of the total population eligible (pregnant women, severely ill person and children less than five years-old are excluded from the total population) in the survey area.

\section{Reported (administrative) coverage}

The coverage calculated from data reported by all drug distributors, with census figures or drug distributor reports used to estimate the population denominator.

\section{Adherence}

Defined as "the extent to which a person's behavior, taking medication, following a diet, and/or executing lifestyle changes, corresponds with agreed recommendations from a health care provider". The five-year adherence was determined in individuals aged 10 years and above, who should have already taken at least five treatments, as the swallowing of ivermectin during each MDA of the five previous years (2010-2014).

\section{Results}

In the three HD, 69 community leaders, 762 heads of households and 83 community drug distributors were interviewed (Fig. 3). The overall median number of inhabitants per household was 4 (Interquartile range (IQR): 3-6), corresponding to 4 (IQR: 3-6) in the Bafia HD, 5 (IQR: 3-6) in the Foumbot-Massangam HD, and 3 (IQR: 2-4), in the Yabassi HD. Women represented $52 \%$ of the 2942 individuals surveyed in the households. The mean age of participants was $25.4 \pm 18.9$ years, 


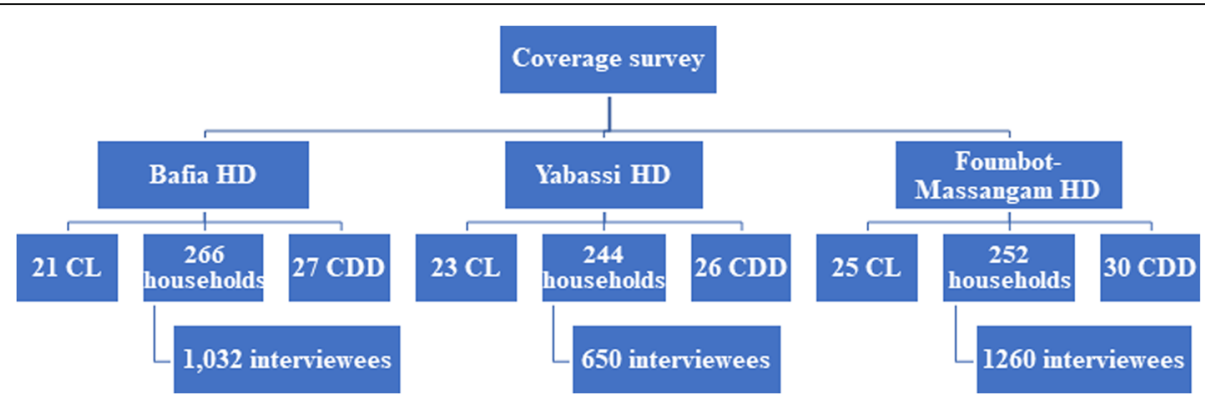

Fig. 3 Flowchart indicating the distribution of participants interviewed. Abbreviations: $C D D$, community drug distributor; $C L$, community leader; $H D$, health district

varying from $22.8 \pm 17.7$ in Foumbot-Massangam HD to $26.7 \pm 20.0$ in Bafia HD and $28.3 \pm 18.8$ in Yabassi HD (ANOVA: $\left.F_{(2,2906)}=21.96, P<0.001\right)$.

\section{CDTI organization}

The organization of CDTI and the involvement of heads of the households were weak in the three HDs as in average $84.0 \%$ (95\% CI: $81.2-86.4 \%$ ) of them declared to not have participated in activities during the 2014 MDA campaign (Fig. 4). This weak participation was most important in the Yabassi HD 88.9\% (95\% CI: 84.3-92.3\%) and in the Bafia HD 87.2\% (95\% CI: 82.6-90.7\%) than in the Foumbot-Massangam HD 75.8\% (95\% CI: 70.180.7\%) $\left(\chi^{2}=27.2, d f=4, P<0.001\right)$.

The same observation about the community participation was made after interviewing the community leaders and the community drug distributors. On average, six out of ten community leaders declared that the period of mass drug administration was decided by the health personnel rather than the community members as recommended (Fig. 5), but no significant difference was found between $\operatorname{HDs}(P=0.33)$. Almost the same proportion of individuals (57.1\%) declared that the community was not involved in the selection of the CDDs. According to CDDs, their selection was made during a community meeting for only $43.4 \%$ of them, the other being mainly chosen by the health personnel $(27.7 \%)$ or by self-selection (14.5\%) (Fig. 6).

All the communities reported the late arrival of drugs usually in the rainy season during the farming period. At the district level, this late arrival was attributed to the late procurement by the National Onchocerciasis Control Programme (NOCP).

\section{Coverage of the 2014 MDA}

The 2014 overall weighted therapeutic coverage was 64.1\% (95\% CI: $56.8-70.9 \%$ ) with almost no difference between women (64.0\%; 95\% CI: 57.3-70.2\%) and men (64.3\%; 95\% CI: 55.7-72.0\%) $\left(F_{(1,89)}=0.02, P=0.73\right)$ (Fig. 7). There was no significant difference between health districts with $61.1 \%$ (95\% CI: 47.7-73.0\%) in the Bafia HD, 65.1\% (95\% CI: 55.8-73.4\%) in the Yabassi HD and $66.0 \% \quad(95 \% \quad \mathrm{CI}: 53.6-76.6 \%)$ in the Foumbot-Massangam $\operatorname{HD}\left(F_{(1.74,154.48)}=0.23, P=0.76\right)$.

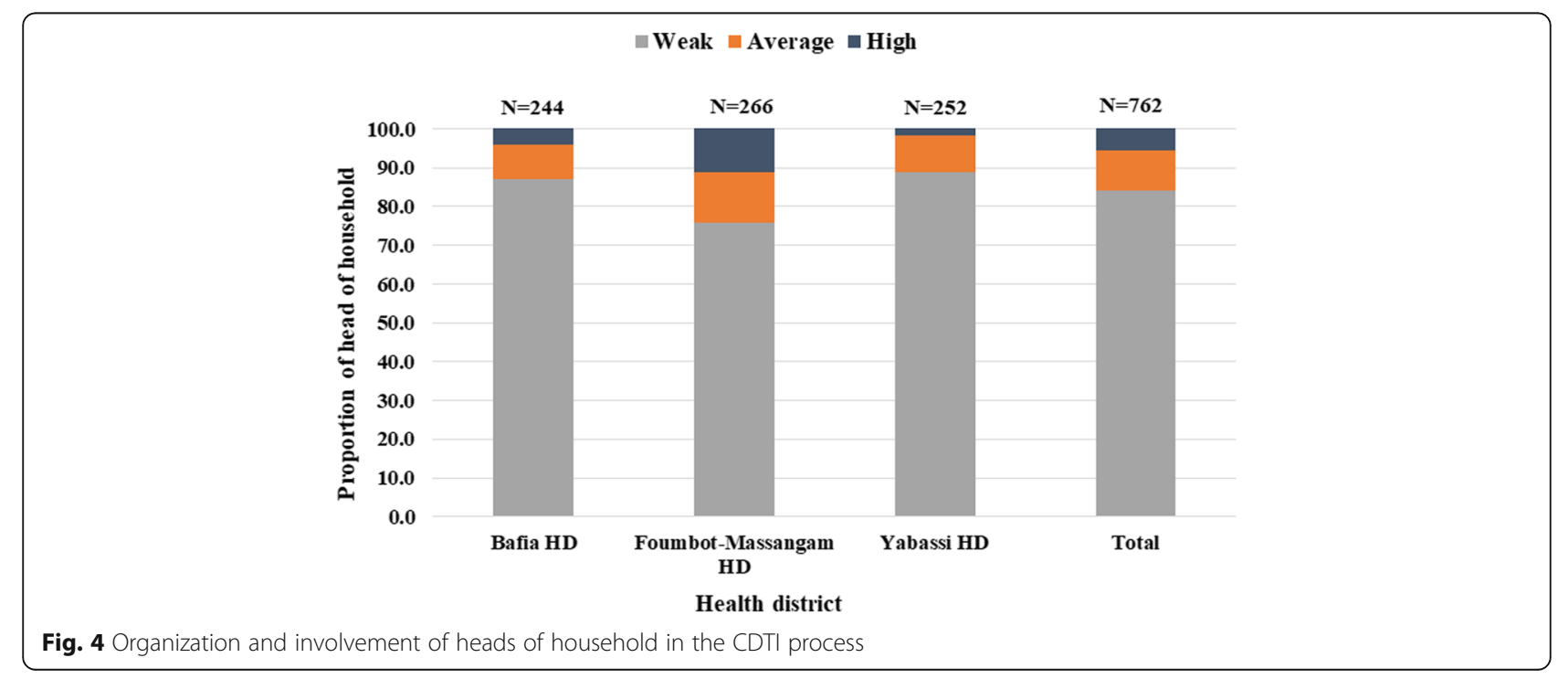




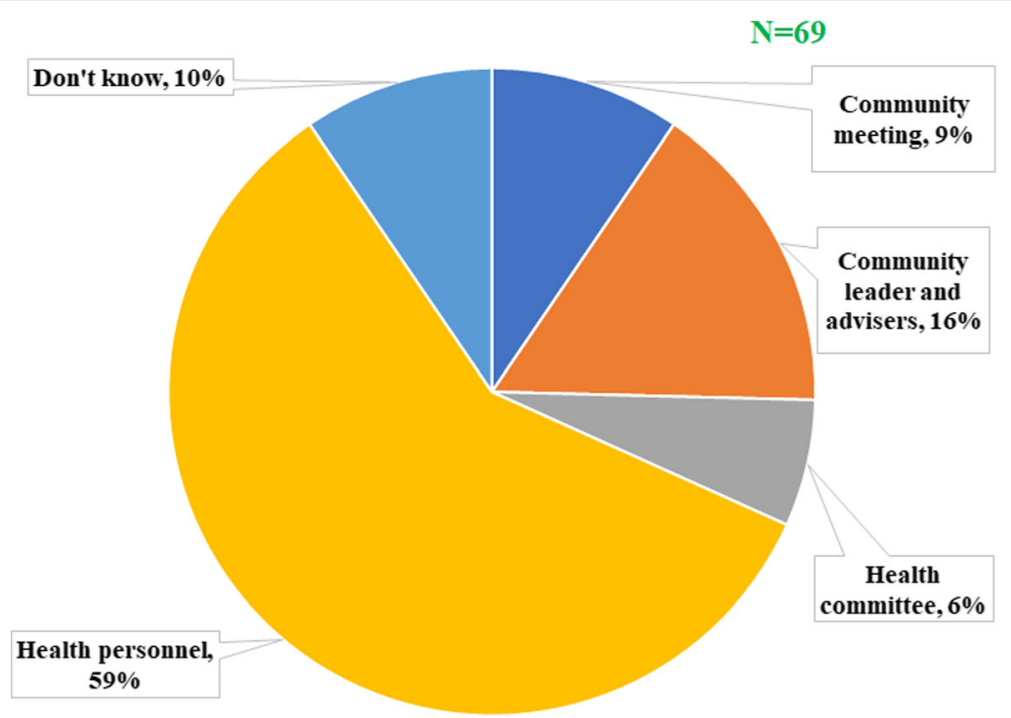

Fig. 5 Actors responsible for the choice of the period of drug distribution according to community leaders

The weighted treatment coverage progressively increased with age, the highest coverages being observed among those aged 40 years and above $\left(F_{(2.46,219.33)}=47.01\right.$, $P<0.001$ ) (Fig. 8). This observation was similar in the three HDs. Private sector workers and their relatives, as well as those leaving in a household where the head was involved in the CDTI, had good therapeutic coverage. The detailed coverages in the three HDs according to participant characteristics are presented in Table 1. The 2014 coverages reported by the health system were higher than the observed during the survey. These differences varied from $14.1 \%$ in Foumbot-Massangam HD to $22.0 \%$ in Bafia HD $\left(\chi^{2}=558.22, d f=25, P<0.001\right)$ (Fig. 9).
The 2014 overall weighted programmatic coverage was 74.4\% (95\% CI: 65.7-81.5\%), with no difference between women $(74.1 \%)$ and men $(74.7 \%)\left(F_{(1,89)}=0.10\right.$, $P=0.76)$. These programmatic coverages varied from 69.1\% (95\% CI: $53.3-81.5 \%$ ) in the Bafia HD to $74.4 \%$ (95\% CI: 65.3-81.8\%) in Yabassi HD, and 78.7\% (95\% CI: 62.4-89.1\%) in the Foumbot-Massangam HD $\left(F_{(1.63 \text {, }}\right.$ 145.38) $=0.66, P=0.45)$.

Among those not treated in 2014, the reasons of non-treatment were assessed. In general, the main reasons were absence $(42.1 \%)$ and refusal $(6.5 \%)$. It should be mentioned that $5.0 \%$ of these untreated declared that they were not aware or not visited by the CDDs. The absence was the main reason evoked in the three HDs.

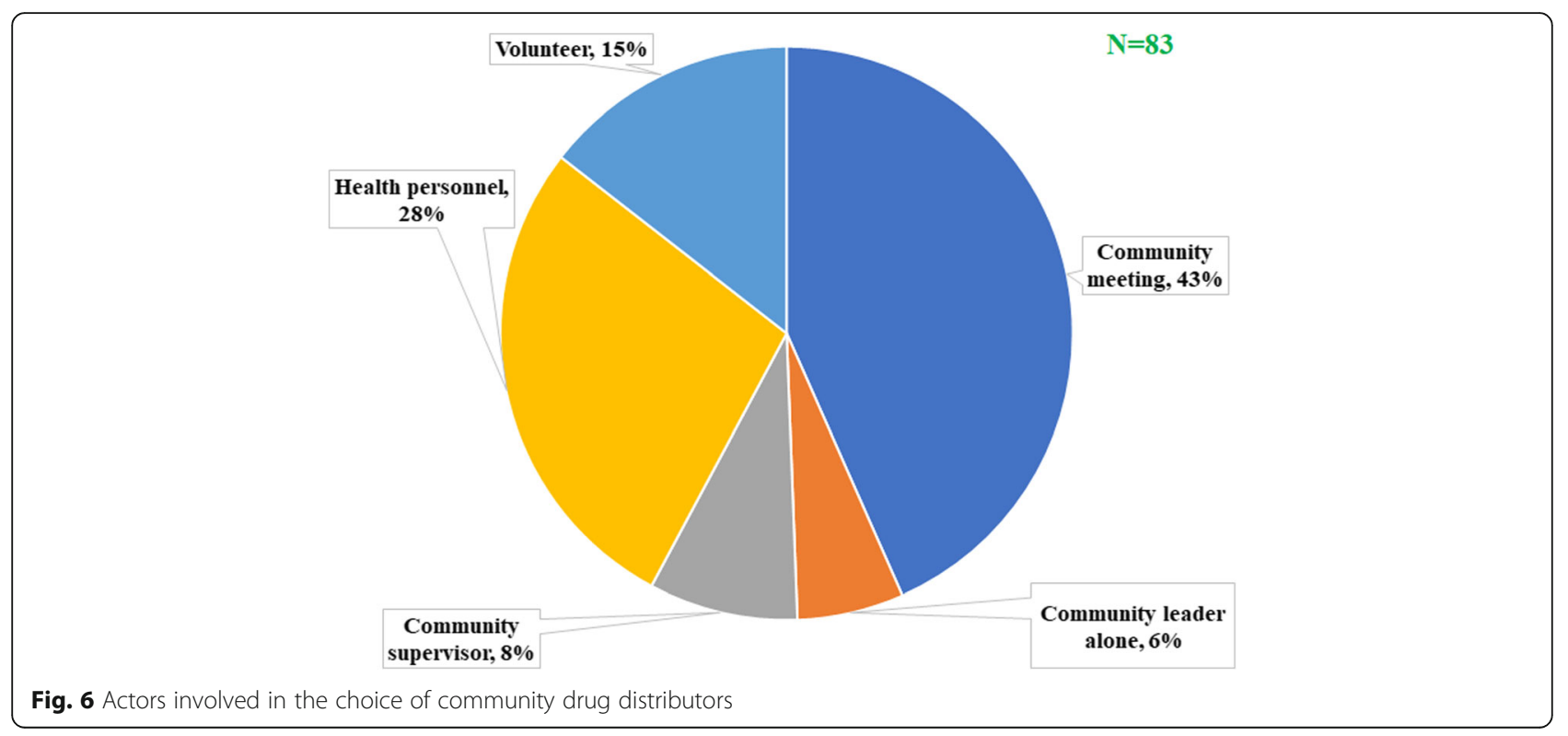




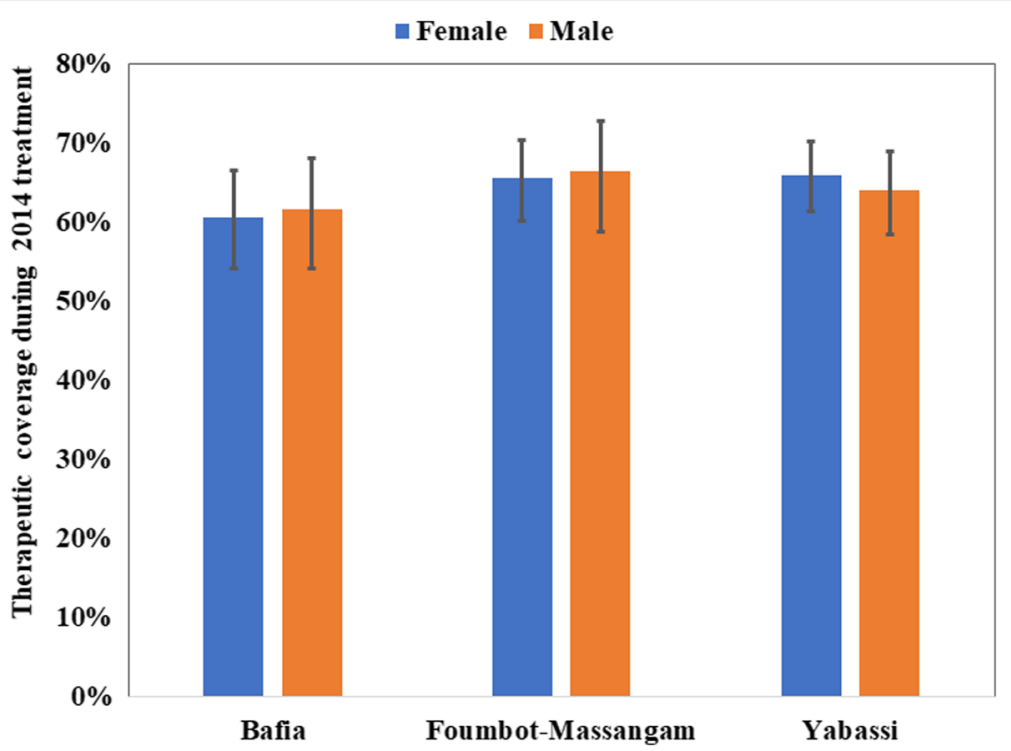

Fig. 7 Therapeutic coverage during 2014 MDA by gender in the three districts (I-bars represent standard errors)

However, in the Yabassi HD, refusals (17.2\%) and the non-visits of the household (16.1\%) were also important reasons. Non-eligible participants (less than 5 years old and pregnant women) at the time of the MDA represented $41.8 \%$ of untreated. Other reasons like shortage in ivermectin supply, payment requirement, belief of the inefficacy of ivermectin, and chronic illness were among reasons evoked by $4.6 \%$ of these untreated participants (Fig. 10).

\section{Adherence to ivermectin mass treatments}

During our survey, $57.8 \%$ (95\% CI: $50.2-65.1 \%$ ) of the participants aged 10 years and above declared having taken ivermectin every time during the last five MDAs with almost no difference between women (57.3\%; 95\% CI: 49.9-64.5\%) and men (58.4\%; 95\% CI: 49.7-66.6\%) $\left(F_{(1,89)}\right.$ $=0.18, P=0.67$ ) (Fig. 11). This proportion was higher in Foumbot-Massangam HD (64.0\%; 95\% CI: 50.6-75.6\%) than in Bafia HD (56.4\%; 95\% CI: 42.9-68.9\%), and Yabassi HD (48.5\%; 95\% CI: 38.4-58.7\%), but the difference was not significant $\left(F_{(1.80,160.39)}=1.45, P=0.24\right)$. The weighted five-year adherence progressively increased with age, the highest adherence being observed among those aged 40 years and above $\left(F_{(3.17,281.77)}=4.26, P=0.005\right)$ (Fig. 12). This observation was similar in the three HDs.

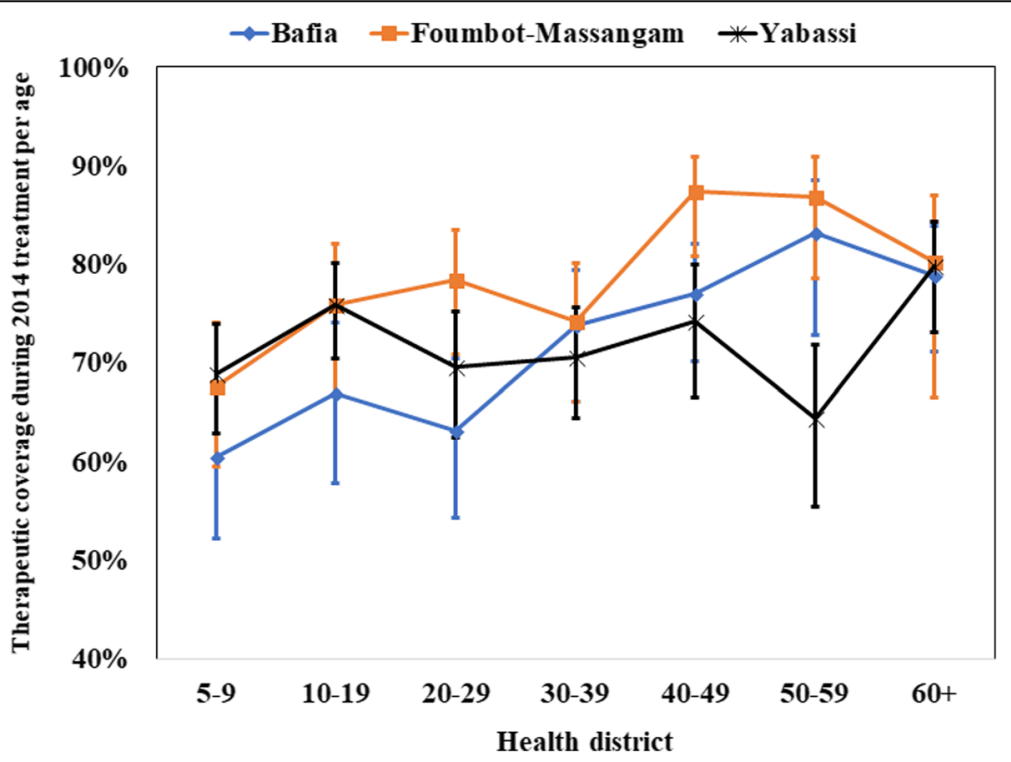

Fig. 8 Therapeutic coverage during 2014 MDA by age in the three districts (I-bars represent standard errors) 
Table 1 The 2014 therapeutic coverage survey according to the characteristics of participants in each health district

\begin{tabular}{|c|c|c|c|c|c|c|c|c|c|}
\hline & \multicolumn{3}{|l|}{ Bafia HD } & \multicolumn{3}{|c|}{ Foumbot-Massangam HD } & \multicolumn{3}{|c|}{ Yabassi HD } \\
\hline & $n$ & $\%(95 \% \mathrm{Cl})$ & $P$ & $n$ & $\%(95 \% \mathrm{Cl})$ & $P$ & $n$ & $\%(95 \% \mathrm{Cl})$ & $P$ \\
\hline Gender & & & 0.74 & & & 0.80 & & & 0.54 \\
\hline Female & 531 & $60.6(47.8-72.1)$ & & 646 & $65.6(55.0-74.9)$ & & 337 & $66.0(56.8-74.2)$ & \\
\hline Male & 496 & $61.6(46.9-74.4)$ & & 594 & $66.5(51.4-78.8)$ & & 305 & $64.0(53.2-73.6)$ & \\
\hline Age category (years) & & & $<0.001$ & & & $<0.001$ & & & $<0.001$ \\
\hline $0-4$ & 82 & Non-eligible & & 149 & Non-eligible & & 57 & Non-eligible & \\
\hline $5-9$ & 152 & $60.5(44.1-74.7)$ & & 194 & $67.6(51.8-80.2)$ & & 55 & $68.9(57.0-78.7)$ & \\
\hline $10-19$ & 245 & $66.9(49.2-80.9)$ & & 320 & $75.9(57.8-87.9)$ & & 137 & $75.9(65.2-84.1)$ & \\
\hline $20-29$ & 160 & $63.1(45.8-77.5)$ & & 193 & $78.5(63.5-88.4)$ & & 123 & $69.6(55.5-80.7)$ & \\
\hline $30-39$ & 126 & $73.8(58.6-84.8)$ & & 153 & $74.3(58.3-85.7)$ & & 89 & $70.6(58.5-80.4)$ & \\
\hline $40-49$ & 105 & $77.1(63.4-86.8)$ & & 103 & $87.4(74.4-94.3)$ & & 74 & $74.3(58.9-85.4)$ & \\
\hline $50-59$ & 71 & $83.2(62.8-93.6)$ & & 76 & 86.9 (70.7-94.8) & & 56 & $64.4(46.8-78.9)$ & \\
\hline $60+$ & 86 & $78.8(63.7-88.7)$ & & 52 & $80.2(53.3-93.5)$ & & 51 & $79.8(66.7-88.7)$ & \\
\hline \multicolumn{3}{|c|}{ Participants according to the profession of the head of household } & 0.21 & & & 0.005 & & & 0.14 \\
\hline Civil servant & 99 & $51.1(35.5-66.5)$ & & 134 & $74.3(61.9-83.7)$ & & 67 & $75.4(56.7-87.8)$ & \\
\hline Private sector worker & 27 & $72.0(47.3-88.0)$ & & 37 & $93.4(80.8-98.0)$ & & 19 & $84.3(69.6-95.4)$ & \\
\hline Farmer & 611 & $65.4(49.7-78.3)$ & & 603 & $63.5(46.5-77.7)$ & & 240 & $59.2(44.7-72.2)$ & \\
\hline Trader & 72 & $65.4(40.8-83.8)$ & & 136 & $84.0(77.3-88.9)$ & & 30 & $80.8(66.9-89.8)$ & \\
\hline Unskilled worker & 52 & $61.2(32.4-83.8)$ & & 106 & $47.8(24.3-72.4)$ & & 89 & $70.9(52.9-84.0)$ & \\
\hline Jobless & 163 & $46.7(28.2-66.1)$ & & 219 & $62.1(54.0-69.5)$ & & 190 & $61.1(47.4-73.2)$ & \\
\hline \multicolumn{3}{|c|}{ Participants according to the educational level of the head of household } & 0.28 & & & 0.09 & & & 0.59 \\
\hline Never attended school & 83 & $76.6(49.6-91.6)$ & & 83 & $52.8(26.2-77.9)$ & & 45 & $52.7(21.5-81.9)$ & \\
\hline Primary school & 422 & $60.4(43.8-74.9)$ & & 572 & $69.0(54.8-80.4)$ & & 243 & $64.1(51.6-75.0)$ & \\
\hline Secondary school & 469 & $60.8(45.1-74.6)$ & & 540 & $62.7(50.0-73.8)$ & & 299 & $66.1(56.5-74.5)$ & \\
\hline University & 51 & $48.2(28.7-68.2)$ & & 45 & $93.7(61.0-99.3)$ & & 52 & $74.0(53.5-87.6)$ & \\
\hline \multicolumn{3}{|c|}{ History of side effects during past treatments } & 0.23 & & & 0.97 & & & 0.045 \\
\hline No & 935 & $63.5(48.8-76.0)$ & & 1174 & $67.5(54.1-78.5)$ & & 550 & $65.1(54.3-74.5)$ & \\
\hline Yes & 59 & $51.1(29.7-72.1)$ & & 32 & $67.9(39.8-87.1)$ & & 72 & $80.4(65.6-89.8)$ & \\
\hline \multicolumn{3}{|c|}{ Perception of the risk to catch onchocerciasis } & 0.54 & & & 0.005 & & & 0.50 \\
\hline No & 266 & $66.6(47.9-81.3)$ & & 376 & $81.2(73.9-86.8)$ & & 134 & $61.0(47.2-73.2)$ & \\
\hline Yes & 757 & $59.4(43.0-74.0)$ & & 859 & $59.7(44.0-73.6)$ & & 508 & $66.2(55.5-75.4)$ & \\
\hline \multicolumn{2}{|l|}{ Involvement of parents in CDTI } & & 0.006 & & & $<0.001$ & & & $<0.001$ \\
\hline High & 51 & $93.0(75.8-98.3)$ & & 109 & $94.4(86.1-97.9)$ & & 18 & $88.6(69.5-96.4)$ & \\
\hline Average & 91 & $66.0(47.8-80.4)$ & & 193 & $84.3(74.7-90.8)$ & & 79 & $88.5(76.2-94.9)$ & \\
\hline Low & 885 & $58.9(44.7-71.8)$ & & 938 & $59.6(45.6-72.1)$ & & 545 & $61.0(51.2-69.9)$ & \\
\hline General therapeutic coverage & 1027 & $61.1(47.7-73.0)$ & & 1240 & $66.0(53.6-76.6)$ & & 642 & $65.1(55.8-73.4)$ & $0.76^{*}$ \\
\hline
\end{tabular}

Among these participants, 9.8\% (95\% CI: 7.5-12.8\%) declared having not taken the drug during the last five MDAs. This proportion was higher in Yabassi HD (15.4\%; 95\% CI: $11.5-20.5 \%)$ than in Bafia HD (10.0\%; 95\% CI: 5.9-16.4\%) and Foumbot-Massangam HD (6.8\%; 95\% CI: 3.8-11.6\%). Among these non-adherent participants, $53 \%$ were females; $75 \%$ were less than 40 years-old; $98 \%$ had a weak involvement in the CDTI process and $67 \%$ were farmers or jobless. The characteristics of these participants are summarized in Table 2. The reasons of non-treatment given by persons not treated varied a lot: fear of the side effects, non-trust to the efficacy of ivermectin, non-trust to the CDDs, absence due to farming, distribution during an unsuitable period for the community, shortage in ivermectin, payment requirement, although it 


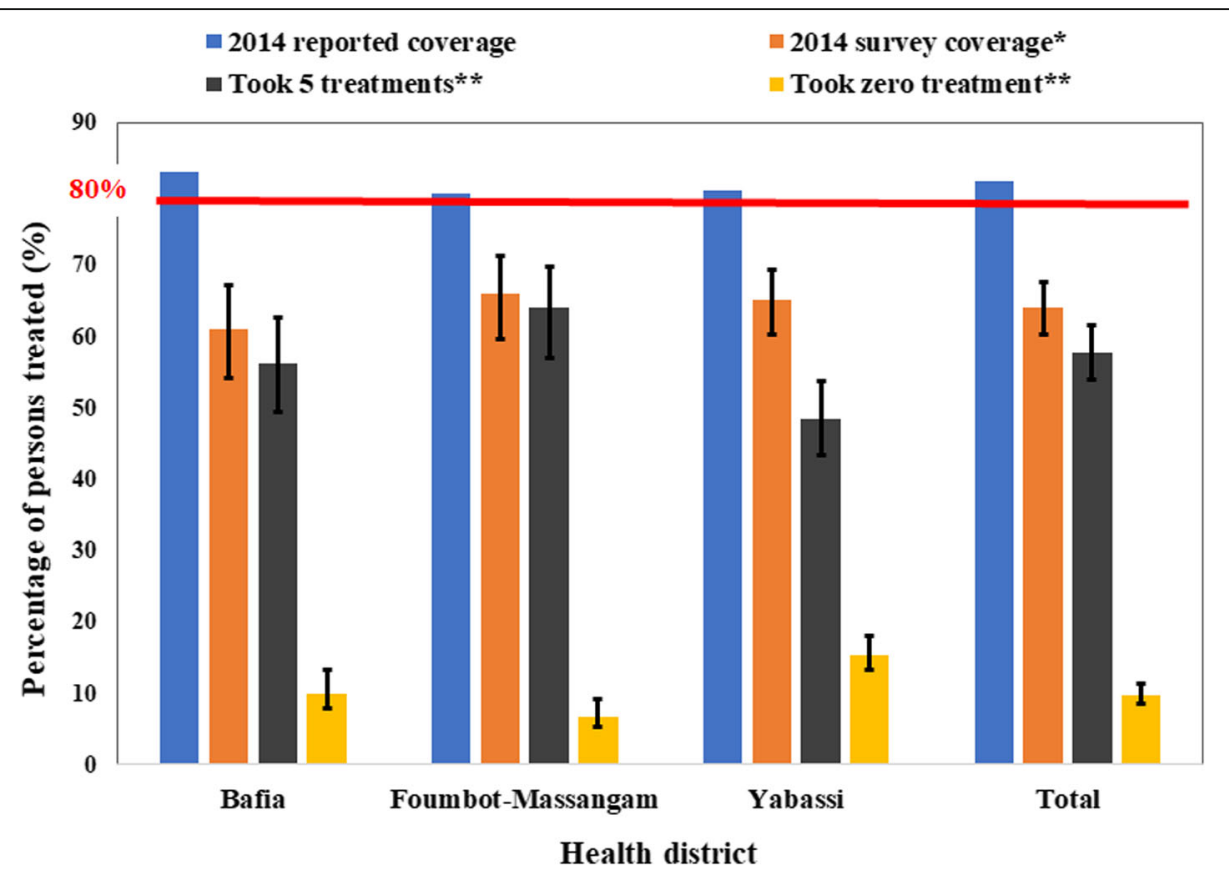

Fig. 9 Therapeutic coverage during 2014 MDA and therapeutic adherence during the last five treatments (I-bars represent standard errors)

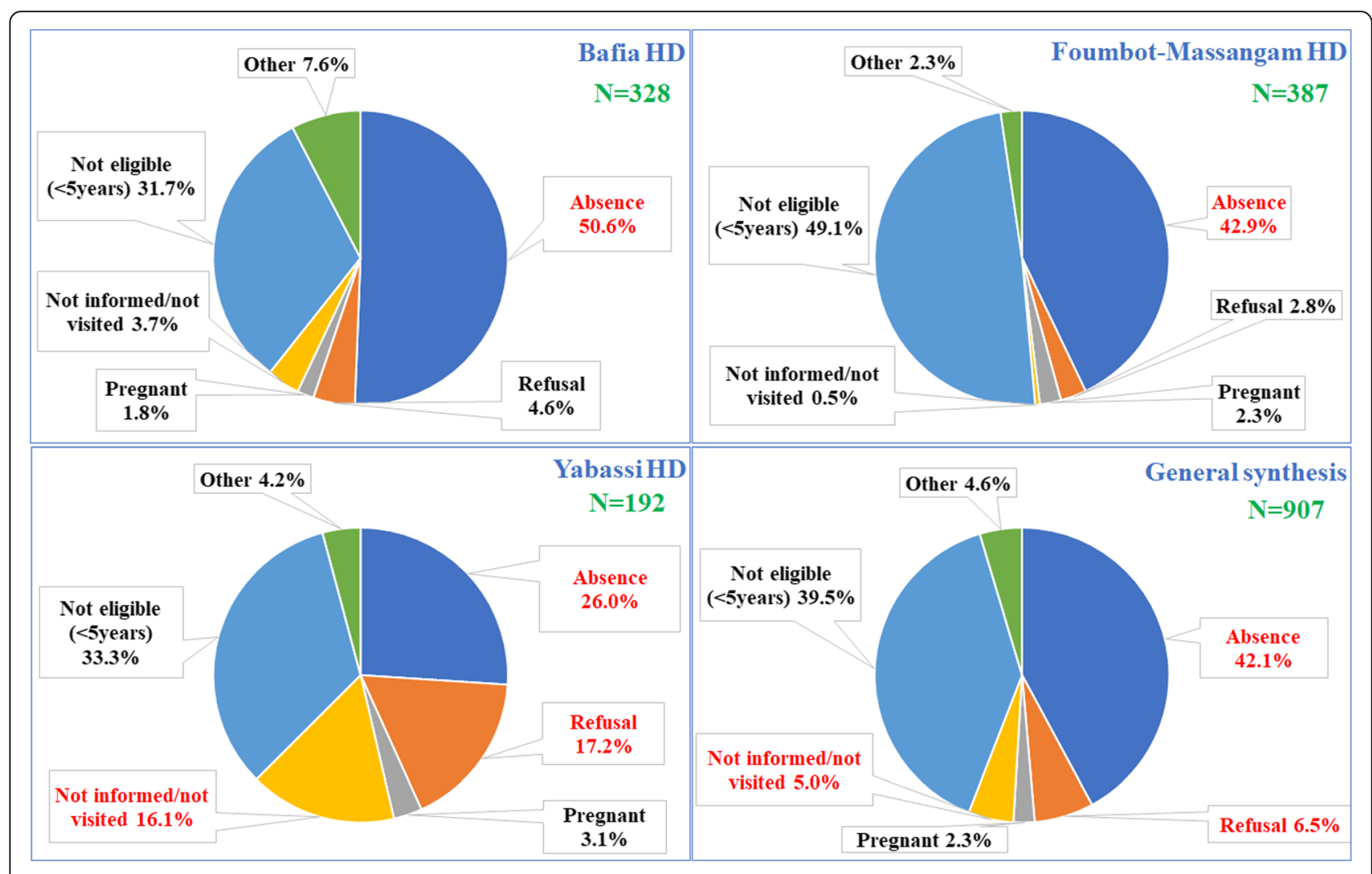

Fig. 10 Reasons of non-treatment in the three health districts 


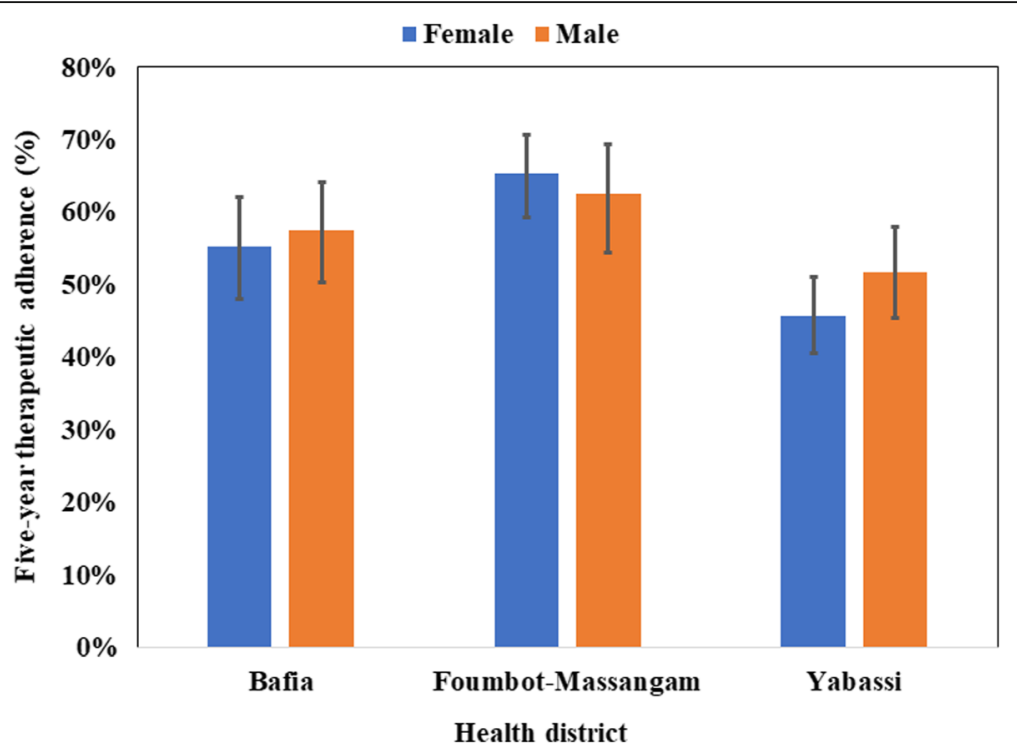

Fig. 11 Five-year therapeutic adherence by gender in the three districts (I-bars represent standard errors)

is known that the distribution is free of charge, temporary illness, as examples

The assessment of the determinants of the five-year adherence revealed that age (above 50 years), the profession of the heads of households (private sector worker), the perception of the risk to be infected and a high involvement in CDTI activities were the most favorable characteristics (Table 3). In the multivariate logistic regression, high involvement in the CDTI process (adjusted odds ratio, AOR: 19.01; 95\% CI: 6.09-59.32) and age (40+ years, AOR: 1.58 ; 95\% CI: $1.26-1.99)$ were the factors associated with the five-year adherence to treatments (Table 4).

\section{Discussion}

The objective of the present survey was to investigate the reasons why onchocerciasis was persisting in the Centre 1, Littoral 2 and West CDTI projects by assessing: (i) the implementation of the CDTI; (ii) the 2014 MDA coverage; and (iii) the factors influencing the adherence to the treatment in three HDs selected in the targeted CDTI projects. This assessment was conducted before the publication of the 2016 new WHO field guide for implementation of coverage evaluation surveys for preventive chemotherapy [25]. However, our methodology was based

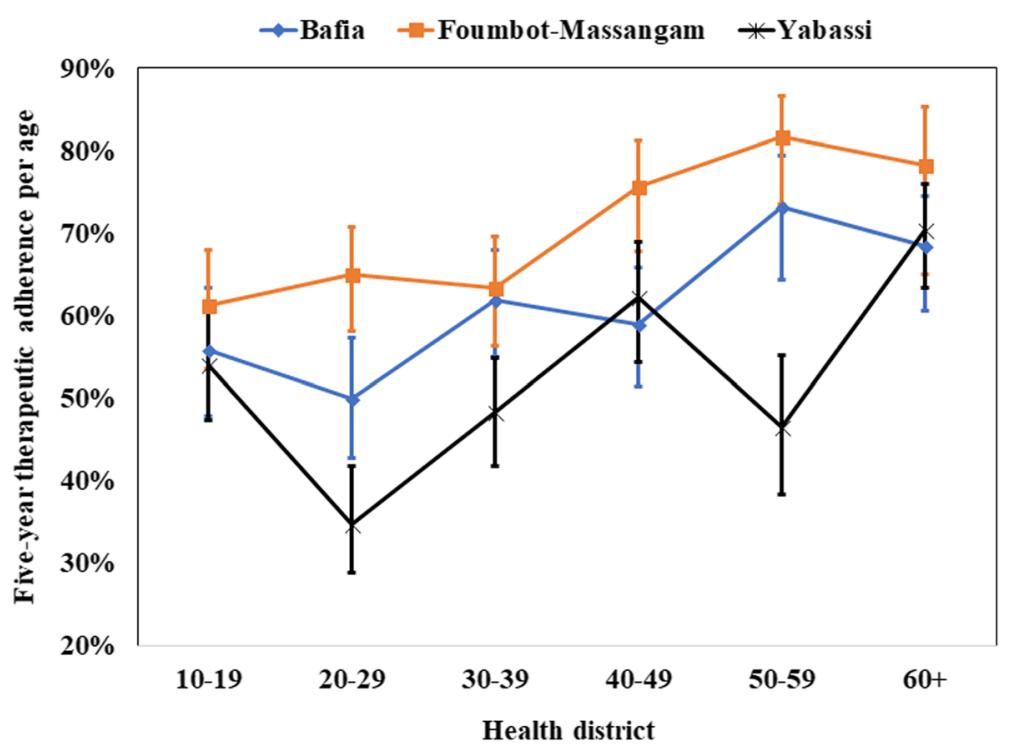

Fig. 12 Five-year therapeutic adherence by age in the three districts (I-bars represent standard errors) 
Table 2 Characteristics of systematic non-adherents

\begin{tabular}{|c|c|c|}
\hline & $n=222$ & $\%$ \\
\hline \multicolumn{3}{|l|}{ Gender } \\
\hline Female & 118 & 53.1 \\
\hline Male & 104 & 46.9 \\
\hline \multicolumn{3}{|l|}{ Age category (years) } \\
\hline $10-19$ & 66 & 29.7 \\
\hline $20-29$ & 55 & 24.8 \\
\hline $30-39$ & 37 & 16.7 \\
\hline $40-49$ & 25 & 11.3 \\
\hline $50-59$ & 17 & 7.7 \\
\hline $60+$ & 9 & 4.0 \\
\hline Missing & 13 & - \\
\hline \multicolumn{3}{|c|}{ Participants according to the profession of the head of household } \\
\hline Civil servant & 30 & 13.5 \\
\hline Private sector worker & 2 & 0.9 \\
\hline Farmer & 80 & 36.0 \\
\hline Trader & 15 & 6.8 \\
\hline Unskilled worker & 25 & 11.3 \\
\hline Jobless & 68 & 30.6 \\
\hline Missing & 2 & - \\
\hline \multicolumn{3}{|c|}{ Participants according to the educational level of head of household } \\
\hline Never attended school & 13 & 5.9 \\
\hline Primary school & 87 & 39.2 \\
\hline Secondary school & 104 & 46.8 \\
\hline University & 17 & 7.7 \\
\hline Missing & 1 & - \\
\hline \multicolumn{3}{|c|}{ History of side effects during pass treatments } \\
\hline No & 204 & 91.9 \\
\hline Yes & 6 & 2.7 \\
\hline Missing & 12 & - \\
\hline \multicolumn{3}{|c|}{ Perception of the risk to catch onchocerciasis } \\
\hline No & 62 & 27.9 \\
\hline Yes & 160 & 72.1 \\
\hline \multicolumn{3}{|c|}{ Implication of parents in CDTI } \\
\hline High & 0 & 0 \\
\hline Average & 5 & 2.3 \\
\hline Low & 217 & 97.7 \\
\hline
\end{tabular}

Abbreviation: CDTI community-directed treatment with ivermectin

on the well-known cluster survey method used by the Expanded Program on Immunization $[17,18]$.

In the three HDs, the interviews of the community leaders, the CDDs, and the heads of households revealed a weak community participation and ownership of the CDTI process. As recommended by the former APOC in the practical guide for the implementation of the CDTI, the selection of CDDs, the choice of the period of distribution among other processes should be made by the community members themselves [26]. In the surveyed HDs, these processes were mainly conducted by others (health personnel) rather than the community members. Consequently, the distribution period sometimes coincided with the farming activities, as declared by participants who were absent during the visit of the CDD. Furthermore, those who refused to take the treatment argued that the side-effects limited their ability to work while others mentioned that they did not trust the CDDs they had not chosen. As mentioned by many authors, a high community participation, ownership, good perception of the CDTI are associated with high coverages and a good adherence [24, 27-30], leading to a better control and a reduction of the transmission of onchocerciasis. The same observation was made in the three surveyed HDs as a high involvement in the CDTI had the highest predictive value of a good adherence. These findings emphasized the importance of the empowerment of the community participation by the Ministry of Health. If the community really decides on how and when to conduct the CDTI, its engagement will surely improve. Community leaders said that they did not see the importance of a better engagement if, at the end, community decisions will not be taken into account.

There was a great difference between the observed and the reported treatment coverage in 2014, ranging from 14\% (Foumbot-Massangam HD) to 22\% (Bafia HD). This difference can be attributed to many factors: an incomplete census leading to an underestimation of the total population, a misreporting of persons treated either voluntary or unintentionally, the refusal to treat some community members by the CDD due to interpersonal conflict, the demotivation of CDDs with impact on the quality of their work, as examples.

Unfortunately, the CDDs registries were not available to check the concordance of the data. However, we reported the same lower coverages in different settings in the same HDs [31-33]. Such over-reporting in the treatment coverage can bias or overestimate the success of CDTI thereby inhibiting all actions that can help improve the situation such as the reinforcement of the community empowerment and CDTI ownership. As mentioned earlier, the involvement of community leaders and heads of households in the CDTI also had a great effect on the treatment. In general, the coverages increased with age in the three HDs, as it is likely that the oldest who witnessed the consequences of the disease when its burden was high, before the start of control measures were therefore aware of the importance of treatment. Even though their number was low, household members from private sector had a better coverage. Private sector worker was defined 
Table 3 Five-year therapeutic adherence of persons 10 years and above in the surveyed districts

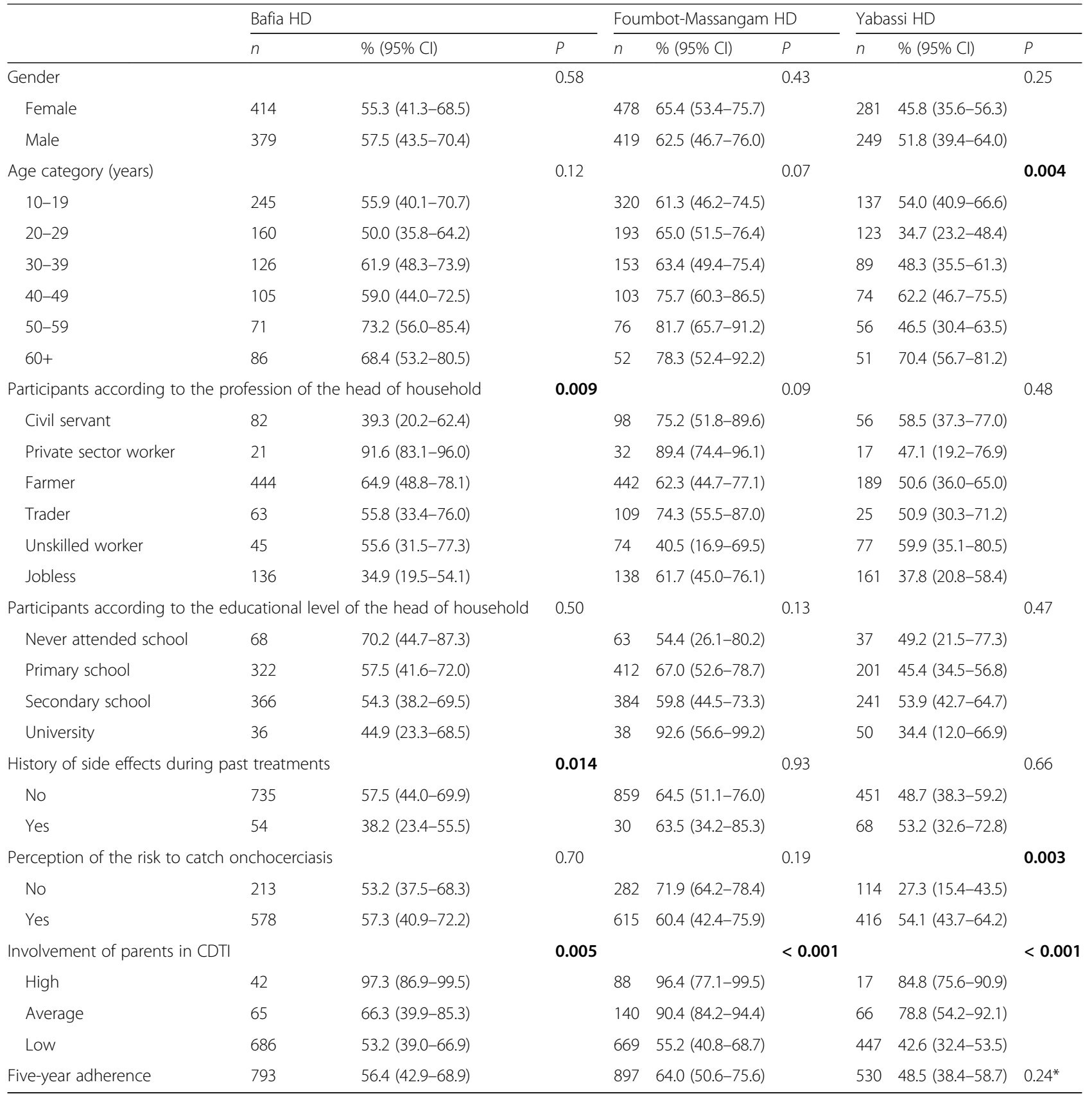

Abbreviations: $H D$ health district, CDTI community-directed treatment with ivermectin; In bold: $P$-value $<5 \%$; ${ }^{*}$-value of the comparison between the three HDs

as someone not paid by the government, but who received a salary at the end of the month from his employer. Due to the employment precarity and the scarcity of a stable paid work, private sector workers usually do anything possible to stay healthy and preserve their job. This is probably the reason motivating them to take the treatment and invite their relatives to do the same.

The effect of the educational level, the history of side effect during past treatments, as well as the perception of the risk to be infected by the disease on the adherence to treatment varied among the HDs.

Concerning the five-year adherence, $58 \%$ of participants declared having taken five treatments during the last five years while $10 \%$ of the participants did not take any treatment. Irregularly treated persons can constitute a reservoir for the disease transmission and be a threat to the disease elimination. Combined with other factors like the high transmission due to very high fly density and biting rates, this treatment irregularity can 
Table 4 Predictive variables of the five-year adherence in multivariate logistic regression

\begin{tabular}{lll}
\hline Predictors variables & Adjusted odds ratio $(95 \% \mathrm{Cl})$ & $P$ \\
\hline $\begin{array}{l}\text { Involvement in CDTI } \\
\text { High }\end{array}$ & $19.01(6.09-59.32)$ & $<0.001$ \\
Average & $4.38(2.38-8.08)$ & \\
Low & 1 & $<0.001$ \\
Age (years) & & \\
Less than 40 & 1 & \\
40 and above & $1.58(1.26-1.99)$ & \\
\hline
\end{tabular}

Abbreviation: CDTI, community-directed treatment with ivermectin

constitute an important reason explaining the persistence of the disease. It is worth mentioning that the better adherence recorded in the Foumbot-Massangam HD (64\%), can explain at least, partially, the progress towards elimination observed in the West CDTI project [31]. The lower adherence observed in Yabassi and Bafia $\mathrm{HD}$ is likely to be among the main reasons explaining the persistence of the disease as recently reported [33]. With the observed adherence, the likelihood for the program to achieve elimination of the disease by 2025 is quite low. The factors independently associated with a good adherence in multivariate analysis were high parent involvement in the CDTI process (AOR: 19.01; 95\% CI: 6.09-59.32) and age (40+ years, AOR: 1.58; 95\% CI: 1.26-1.99).

The main limitation of our study was the fact that surveys were conducted six to nine months after the 2014 treatment, instead of being conducted one to three months after its completion to limit the recall bias. Data for the previous years were also subject to recall bias. However, we believe that our results regarding the therapeutic coverage and the adherence are reliable because ivermectin tablets are special, by both their physical presentation (small and white) and their delivery strategy. So, the likelihood to confuse them with other drugs or interventions is quite low. Brieger et al. [11] reported that $94 \%$ of participants were able to recall the number of times they took ivermectin during the previous eight years. Previous studies have also reported accurate recall of populations when compared to the data from CDTI collected in treatment registries [11, 34-36].

\section{Conclusions}

The implementation of the community-directed treatment with ivermectin was not done as recommended in the surveyed health districts, with a weak community participation or ownership and a low five-year adherence despite more than 15 years since its inception. The reported therapeutic coverages were higher than those observed in the framework of this study and can, therefore, hide the real problems faced by the communities during the implementation of the CDTI, thus inhibiting the implementation of corrective measures. At the country level, the results of this study will help the National Onchocerciasis Control Programme to revise its strategies for the CDTI implementation (respect of the different steps, respect of the roles and responsibilities of the actors, timely procurement of ivermectin, effective supervision and data quality assessment). The findings of this survey were shared with the actors and used for a readjustment of the CDTI implementation. The reinforcement of the community ownership by the Ministry of Public Health officials should be implemented to improve both the coverage and the adherence and hence achieve onchocerciasis elimination. Further anthropological and entomological studies could also provide better insights into our understanding of the persistence of the disease in these three CDTI projects.

\section{Abbreviations}

APOC: African Program for Onchocerciasis Control; ARES-CCD: Académie de Recherche et d'Enseignement Supérieur-Commission de la Coopération au Développement, Belgique; CDD: Community drug distributors;

CDTI: Community-directed treatment with ivermectin; Cl: Confidence interval; CL: Community leader; CRFilMT: Centre for Research on Filariasis and other Tropical Diseases; HD: Health district; IQR: Interquartile range; MDA: Mass drug administration; NOCP: National Onchocerciasis Control Program; WHO: World Health Organization

\section{Acknowledgments}

The authors thank the research assistants who helped to collect data, the staff of the three health districts, the community leaders, the community drug distributors of the surveyed communities, and the other participants for their cooperation.

\section{Funding}

This study was funded by the Belgian University Cooperation (www.ares-ac.be/fr/cooperation-au-developpement) through the PRD2013 collaborative project between Université Catholique de Louvain, Université Libre de Bruxelles, the University of Buea, the Centre for Research on Filariasis and other Tropical Diseases (CRFilMT) and the Ministry of Public Health of Cameroon.

\section{Availability of data and materials}

The data supporting the conclusions of this article are included within the article. Raw data can be obtained upon request.

\section{Authors' contributions}

GRK designed the study, collected field data, performed statistical analyses and drafted the manuscript. FDD and HND participated in the study design and helped to draft the manuscript. BDB provided previous data and helped to draft the manuscript. SG participated in the conception and design of the study and helped to draft the manuscript. JS conceived the study and helped to draft the manuscript. JK conceived and coordinated the study and helped to draft the manuscript. AR conceived and designed the study and helped to draft the manuscript. All authors read and approved the final manuscript.

\section{Ethics approval and consent to participate}

An ethical clearance was obtained from the National Ethics Committee for Human Health Research ( $\left.{ }^{\circ} 2015 / 01 / 543 / C E / C N R E S H / S P\right)$ and an administrative authorization was granted by the Cameroon Ministry of Public Health ( $\mathrm{N}^{\circ} 631$-1315) prior to the beginning of the surveys. The study was also approved by the Ethics committee of the Medical Faculty of Université Catholique de Louvain, Belgium. The objectives and schedules of the study were explained to health district management teams, the community leaders, the community drug distributors and to 
all heads of households selected before requesting a verbal agreement to participate. Participation was entirely voluntary and any individual (or parent of a child) was free to opt out without fear of retaliation from their community leaders and programme personnel.

\section{Consent for publication}

Not applicable.

\section{Competing interests}

The authors declare that they have no competing interests.

\section{Publisher's Note}

Springer Nature remains neutral with regard to jurisdictional claims in published maps and institutional affiliations.

\section{Author details}

${ }^{1}$ Ministry of Public Health, N8, Rue 3038 quartier du Lac, Yaoundé, Cameroon. ${ }^{2}$ Centre for Research on Filariasis and other Tropical Diseases (CRFilMT), P.O. Box 5797, Yaoundé, Cameroon. ${ }^{3}$ Institut de Recherche Expérimentale et Clinique, Faculté de santé publique, Université catholique de Louvain, Clos Chapelle-aux-champs 30 bte B1.30.13, BE-1200 Brussels, Belgium. ${ }^{4}$ Institute of Biology of Molecular Medicine, Rue des professeurs Jeener et Brachet 12 BE-6041 Gosselies, Université Libre de Bruxelles, Brussels, Belgium. ${ }^{5}$ Parasitology and Ecology Laboratory, Faculty of Science, University of Yaoundé 1, POBox 812, Yaoundé, Cameroon. ${ }^{6}$ Molecular and Cell Biology Laboratory, Department of Biochemistry and Molecular Biology, University of Buea, P.O. Box 63, Buea, Cameroon. ${ }^{7}$ Faculty of Medicine and Biomedical Sciences, University of Yaoundé 1, P.O. Box 1364, Yaoundé, Cameroon.

\section{Received: 10 January 2018 Accepted: 7 June 2018}

\section{Published online: 19 June 2018}

\section{References}

1. WHO. Progress report on the elimination of human onchocerciasis, 20152016. Wkly Epidemiol Rec. 2016;91:505-14.

2. WHO. Progress report on the elimination of human onchocerciasis, 20162017. Wkly Epidemiol Rec. 2017;92:681-94.

3. Herricks JR, Hotez PJ, Wanga V, Coffeng LE, Haagsma JA, Basáñez M-G, et al. The global burden of disease study 2013: what does it mean for the NTDs? PLoS Negl Trop Dis. 2017;11:e0005424.

4. Plaisier AP, van Oortmarssen GJ, Remme J, Habbema JD. The reproductive lifespan of Onchocerca volvulus in West African savanna. Acta Trop. 1991;48: 271-84.

5. Duke BO. The population dynamics of Onchocerca volvulus in the human host. Trop Med Parasitol. 1993:44:61-8.

6. WHO-TDR. The involvement of community-directed distributors of ivermectin in other health and development activities-Report of a multicountry study. Geneva: World Health Organization; 2003. http://www.who. int/tdr/publications/tdr-research-publications/ivermect distrib/en/.

7. WHO-TDR. Community-directed interventions for major health problems in Africa - a multi-country study:final report 2008. http://www.who.int/tdr/ publications/tdr-research-publications/community-directed-interventionshealth-problems/en/. Geneva: World Health Organization; 2008.

8. Katabarwa MN, Habomugisha P, Eyamba A, Byamukama E, Nwane P, Arinaitwe $\mathrm{A}$, et al. Community-directed interventions are practical and effective in low-resource communities: experience of ivermectin treatment for onchocerciasis control in Cameroon and Uganda, 2004-2010. Int Health. 2016:8:116-23.

9. Tekle AH, Zoure HG, Noma M, Boussinesq M, Coffeng LE, Stolk WA, Remme $J$ H. Progress towards onchocerciasis elimination in the participating countries of the African Programme for Onchocerciasis Control: epidemiological evaluation results. Infect Dis Poverty. 2016;5:66

10. GTNO-Cameroun. Rapport technique annuel 2014; 2015. Unpublished

11. Brieger WR, Okeibunor JC, Abiose AO, Wanji S, Elhassan E, Ndyomugyenyi R, Amazigo UV. Compliance with eight years of annual ivermectin treatment of onchocerciasis in Cameroon and Nigeria. Parasit Vectors. 2011:4:152.

12. Yirga D, Deribe K, Woldemichael K, Wondafrash M, Kassahun W. Factors associated with compliance with community directed treatment with ivermectin for onchocerciasis control in southwestern Ethiopia. Parasit Vectors. 2010;3:48.
13. Lakwo TL, Gasarasi DB. Non-adherence to community directed treatment with ivermectin for onchocerciasis control in Rungwe District, southwest Tanzania. East Afr Med J. 2006;83:326-32.

14. Semiyaga NB, Lalobo O, Ndyomugyenyi R. Refusal to take ivermectin: the associated 'risk' factors in Hoima district, Uganda. Ann Trop Med Parasitol. 2005:99:165-72.

15. Nuwaha F, Okware J, Ndyomugyenyi R. Predictors of compliance with community-directed ivermectin treatment in Uganda: quantitative results. Trop Med Int Health. 2005;10:659-67.

16. Katabarwa MN, Eyamba A, Nwane P, Enyong P, Kamgno J, Kuete T, et al. Fifteen years of annual mass treatment of onchocerciasis with ivermectin have not interrupted transmission in the west region of cameroon. J Parasitol Res. 2013;2013:420928.

17. WHO. Training for Mid-Level Managers: The EPI Coverage Survey. WHO/IVB/ 08.07 WHO/EPI/MLM. Geneva: World Health Organization; 2008.

18. WHO. Immunization Coverage Cluster Survey- Reference Manual. WHO/IVB/ 04.23; Geneva: World Health Organization; 2005.

19. Worrell C, Mathieu E. Drug coverage surveys for neglected tropical diseases: 10 years of field experience. Am J Trop Med Hyg. 2012;87: 216-22.

20. BUCREP. Projections démographiques du troisième Recensement Général de la Population et de l'Habitat (3ème RGPH) du Cameroun; 2010. http:// www.bucrep.cm/index.php/fr/ressources-et-documentations/ telechargement/category/82-projections-demographiques.

21. Heeringa SG, West BT, Berglund PA. Applied survey data analysis. Boca Raton, FL: Chapman and Hall; 2010.

22. WHO. Monitoring and epidemiological assessment of mass drug administration in the global programme to eliminate lymphatic filariasis: A manual for national elimination programmes. Geneva: World Health Organization; 2011.

23. Krentel A, Fischer PU, Weil GJ. A review of factors that influence individual compliance with mass drug administration for elimination of lymphatic filariasis. PLoS Negl Trop Dis. 2013;7:e2447.

24. Shuford KV, Turner HC, Anderson RM. Compliance with anthelmintic treatment in the neglected tropical diseases control programmes: a systematic review. Parasit Vectors. 2016;9:29.

25. WHO. Coverage evaluation surveys for preventive chemotherapy: field guide for implementation; 2016.

26. WHO/APOC. Community-directed treatment with ivermectin (cdti): a practical guide for trainers of community-directed distributors. Geneva: World Health Organization; 1998.

27. Amazigo U, Okeibunor J, Matovu V, Zoure H, Bump J, Seketeli A. Performance of predictors: evaluating sustainability in community-directed treatment projects of the African programme for onchocerciasis control. Soc Sci Med. 2007;64:2070-82

28. Mbanefo EC, Eneanya Cl, Nwaorgu OC, Oguoma VM, Otiji MO, Ogolo BA. Onchocerciasis in Anambra State, Southeast Nigeria: clinical and psychological aspects and sustainability of community directed treatment with ivermectin (CDTI). Postgrad Med J. 2010;86:573-7.

29. Meredith SE, Cross C, Amazigo UV. Empowering communities in combating river blindness and the role of NGOs: case studies from Cameroon, Mali, Nigeria, and Uganda. Health Res Policy Syst. 2012;10:16.

30. Senyonjo L, Oye J, Bakajika D, Biholong B, Tekle A, Boakye D, et al. Factors associated with ivermectin non-compliance and its potential role in sustaining Onchocerca volvulus transmission in the west region of cameroon. PLoS Negl Trop Dis. 2016;10:e0004905.

31. Kamga GR, Dissak-Delon FN, Nana-Djeunga HC, Biholong BD, Ghogomu SM, Souopgui J, et al. Important progress towards elimination of onchocerciasis in the West region of Cameroon. Parasit Vectors. 2017;10:373.

32. Dissak-Delon FN, Kamga GR, Humblet PC, Robert A, Souopgui J, Kamgno J, et al. Adherence to ivermectin is more associated with perceptions of community directed treatment with ivermectin organization than with onchocerciasis beliefs. PLoS Negl Trop Dis. 2017; 11:e0005849.

33. Kamga GR, Dissak-Delon FN, Nana-Djeunga HC, Biholong BD, MbighaGhogomu S, Souopgui J, et al. Still mesoendemic onchocerciasis in two Cameroonian community-directed treatment with ivermectin projects despite more than 15 years of mass treatment. Parasit Vectors. 2016;9: 581.

34. Brieger WR, Okeibunor JC, Abiose AO, Ndyomugyenyi R, Kisoka W, Wanji S, et al. Feasibility of measuring compliance to annual ivermectin treatment in 
the African Programme for Onchocerciasis Control. Trop Med Int Health. 2007;12:260-8

35. Wanji S, Kengne-Ouafo JA, Esum ME, Chounna PW, Adzemye BF, Eyong JE, et al. Relationship between oral declaration on adherence to ivermectin treatment and parasitological indicators of onchocerciasis in an area of persistent transmission despite a decade of mass drug administration in Cameroon. Parasit Vectors. 2015;8:667.

36. Budge PJ, Sognikin E, Akosa A, Mathieu EM, Deming M. Accuracy of coverage survey recall following an integrated mass drug administration for lymphatic filariasis, schistosomiasis, and soil-transmitted helminthiasis. PLoS Negl Trop Dis. 2016;10:e0004358.

Ready to submit your research? Choose BMC and benefit from:

- fast, convenient online submission

- thorough peer review by experienced researchers in your field

- rapid publication on acceptance

- support for research data, including large and complex data types

- gold Open Access which fosters wider collaboration and increased citations

- maximum visibility for your research: over $100 \mathrm{M}$ website views per year 